\title{
Evaluating the potential of capillary rise for the migration of Pt nanoparticles in Luvisols and Phaeozems (Western Siberia)
}

\author{
Sergey Loiko ${ }^{*}$, Alexandr Konstantinov², Georgy Istigechev ${ }^{1}$, Elizaveta Konstantinova ${ }^{3}$, Daria Kuzmina ${ }^{1}$, \\ Vladimir Ivanov ${ }^{2}$, Sergey Kulizhskiy ${ }^{1}$ \\ ${ }^{1}$ BioGeoClim Laboratory, National Research Tomsk State University, 36, Lenina Ave. Tomsk 634050, Russia \\ ${ }^{2}$ The Institute of Environmental and Agricultural Biology (X-BIO), University of Tyumen, 6 Volodarskogo St., Tyumen 625003, Russia \\ ${ }^{3}$ Academy of Biology and Biotechnologies, Southern Federal University, 105/42 Bolshaya Sadovaya Str., Rostov-on-Don 344006, Russia \\ * Sergey Loiko PhD, s.loyko@yandex.ru, ORCID iD: https://orcid.org/0000-0003-2020-4716
}

Received: 19.12.2020

Accepted: 26.08.2021

Associated editor: J. Waroszewski

\section{Keywords}

Platinum nanoparticles

Capillary rise

Luvisols

Phaeozems

Western Siberia

\begin{abstract}
Numerous experiments with nanoparticles have recently led to a better understanding of the migration of colloids and larger particles in soils. However, it remains unclear how colloidal particles migrate in soil horizons without macropores, and whether they can move with the flow of capillary water. In this article, we tested the hypothesis that colloidal particles can be transported by water flow in capillary-sized soil pores. To test our hypothesis, column experiments with platinum nanoparticles were carried out. The columns contained undisturbed monoliths from the Luvisols and Phaeozems soil horizons in the southeast of Western Siberia. The lower part of the soil columns was immersed in a colloidal solution with platinum nanoparticles. Thus, we checked whether the nanoparticles would rise to the top of the columns. Platinum nanoparticles are a usable tracer of colloidal particle migration pathways. Due to the minimal background concentrations, platinum can be detected by inductively coupled plasma mass spectrometry (ICP-MS) in experimental samples. Due to their low zeta potential, nanoparticles are well transported over long distances through the pores. Our experiments made it possible to establish that the process of the transfer of nanoparticles with a flow of capillary water is possible in almost all the studied horizons. However, the transfer distances are limited to the first tens of centimeters. The number of migrating nanoparticles and the distance of their transfer increase with an increase in the minimum moisture-holding capacity and decrease with an increase in the bulk density of soil horizons and an increase in the number of direct macropores. The migration of nanoparticles in capillary pores is limited in carbonate soil horizons. The transfer of colloidal particles through soil capillaries can occur in all directions, relative to the gravity gradient. Capillary transport plays an important role in the formation of the ice composition of permafrost soils, as well as in plant nutrition.
\end{abstract}

\section{Introduction}

The rapid development of nanotechnology in recent years has raised the question of the origin, distribution, fate and transport of nanoparticles (NPs) of various chemical elements in the environment. The sources of NPs in the environment are various technological operations, biomedical products, consumer goods, drugs and their delivery systems, etc. (Vance et al., 2015; Hansen et al., 2016; Rajput et al., 2020). Once released into the environment, either as production and consumption waste, or as a by-product of certain processes, NPs or nanoscale materials are increasingly found in various components of the environment (Bundschuh et al., 2018). By their nature, NPs are active at molecular levels; accordingly, there is a danger that their appearance in the environment in case of unintentional release may pose a threat to the health of various organisms including human (Nowack and Bucheli, 2007; Bakshi et al., 2015; Kurwadkar et al., 2015). Therefore, the processes of transport and deposition and the toxic effects of NPs in various components of the environment are considered to be some of the most demanded and actively developing areas in environmental geochemistry (Boxall et al., 2007; Abbas et al., 2020).

Soil acts as one of the main deposition media for NPs and largely determines the paths and intensity of their migration in aquatic environments, including the possibility of further entry into human food chains (Theng and Yuan, 2008; Rodrigues et al., 2016). In addition, it is known that NPs can affect soil chemical and physical properties as well as their biological activity (Rajput et al., 2018a). For example, NPs accumulated in soils are capable of modifying the surface properties of soil particles, 
causing changes in their sorption properties (Dror et al., 2015). Particular attention is paid to metal NPs due to their potential toxicity (Gestel et al., 2010; Cornelis et al., 2014; Rajput et al., 2018b; Shrivastava et al., 2019).

For the reasons listed above, in the last decade, considerable attention has been paid to the mechanisms of the transport of metal NPs in porous media. (Montańo et al., 2014). It should be noted that the mechanisms of migration of metal NPs in artificial homogeneous porous media are well studied (Lecoanet et al., 2004; Ben-Moshe et al., 2010). At the same time, for natural porous media such as soils, which are much more complex and heterogeneous systems compared to model analogs, studies on their geochemical behavior are less common. (Cornelis et al., 2013; Braun et al., 2015; He et al., 2019). In most experimental studies using cylindrical columns, the main emphasis is on the effect of the physical and chemical properties of soils on the intensity of gravitational transfer of NPs, while the possibilities of their migration with capillary waters are practically not considered; however, this aspect may be important for solving a number of ecological and geochemical problems.

Among the metal NPs, platinum nanoparticles (PtNPs) deserve special attention. On the one hand, PtNPs are produced by humans for further application in the medical and chemical industries (Alex and Tiwari, 2015), and on the other hand, they are formed under natural conditions during the weathering of $\mathrm{Au} / \mathrm{Pt}$ deposits (Hough et al., 2008, 2011; Campbell et al., 2015). Stabilized metal NPs can be subjected to dispersion and further transportation in natural waters, and changes in the geochemical conditions of the environment can lead to their deposition and the formation of secondary enrichment zones (Southam et al., 2009; Reith et al., 2010; Reith and Cornelis, 2017; Korshunova and Charykova, 2019). Such zones can form deposits of precious metals or act as a prospecting indicator while conducting soil geochemical surveys
(Perel'man, 1986; Korshunova and Charykova, 2019). In addition, as shown by the results of one study (Reith and Cornelis, 2017), PtNPs are stable in soil solutions and are potentially promising objects for studying pedogenic processes associated with the migration of fine particles. (Kulizhsky et al., 2013, 2017).

The main route through which contaminants enter the native ecosystems is via aerial transport. This transfer involves both solutes and insoluble particles, including nanoscale ones. One of such regions is Western Siberia in Russia, which contains huge native biomes and industrial centers producing insoluble particles which enter the atmosphere (Shevchenko et al., 2020). The aim of this work was to study the possibility of the transfer of PtNPs with a capillary water flow, including such aspects as i) the identification of relationships between the physical and chemical properties of soils and the intensity of this process and ii) the determination of the potential role of capillary processes in assessing the migration of PtNPs in different horizons of soils characteristic for the southwest of Western Siberia (Russia) in the context of an explanation of common pedogenic processes.

\section{Materials and Methods}

\subsection{Field Study and Soil Sampling}

The studies were carried out in the hemiboreal forest zone in the southeast of Western Siberia (Tom-Yaya-Chulym interfluve) (Fig. 1). The studied territory is characterized by the presence of two types of ecosystems. The first type is represented by tall-grass aspen-fir forests (chernevaya taiga) that correspond to the highest positions of the relief (up to $270 \mathrm{~m}$ a.s.l.). The second type of ecosystem is represented by birch-pine grass forests (subtaiga) that correspond to the lower topographic levels (Loyko et al.,

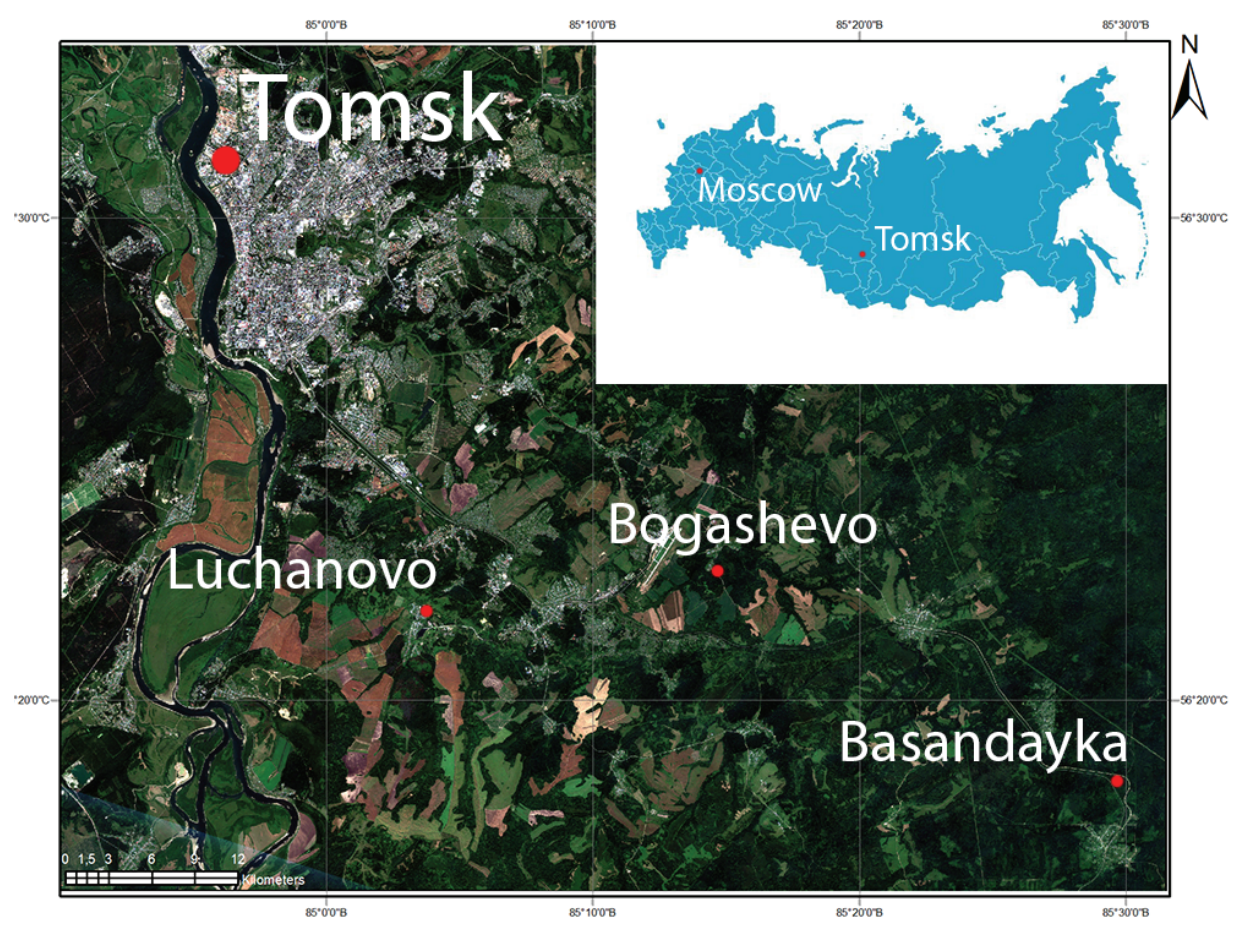

Fig. 1. Study area and key sites of Luchanovo, Bogashevo, Basandayka 


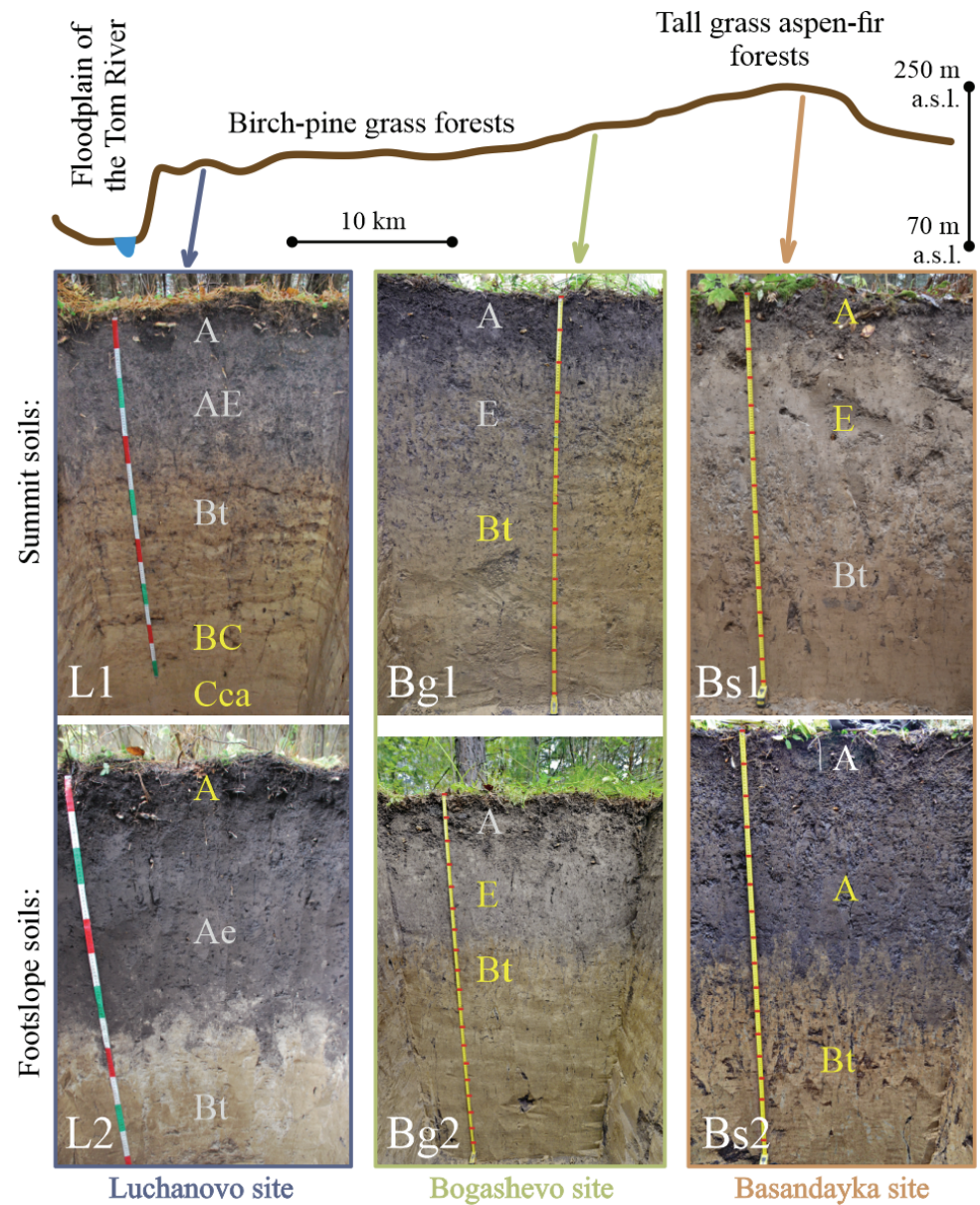

Fig. 2. Altitude profile of the Tom-Yaya interfluve, key sites and photographs of the studied soil profiles: (L1) Luvic Greyzemic Phaeozems (Episiltic, Endoloamic); (L2) Endoluvic Endostagnic Phaeozems (Endoalbic, Amphisiltic, Endoclayic); (Bg1) Amphiluvic Phaeozems (Epialbic, Episiltic, Endoloamic); (Bg2) Albic Luvisols (Episiltic, Endoloamic); (Bs1) Albic Luvisol (Episiltic, Endoclayic, Endocutanic) and (Bs2) Katoluvic Greyzemic Katostagnic Phaeozem (Epiloamic, Endoclayic). The monolith sampling horizons are highlighted in yellow.
2015; Abakumov et al., 2020). The parent materials of the study area are represented by calcareous loess-like clayey mantle with the predominance of clay and coarse silt fractions. The largest areas are occupied by Albic Luvisols and Luvic Phaeozems (Loiko et al., 2015). The soils were selected taking into account the microtopographic catenas. The studied soils were classified according to the WRB (IUSS Working Group WRB 2015) and are shown in Fig. 2. The selected soils are of high interest for the experimental studies described below; in addition, the migration of fine material and the eluvial-illuvial differentiation of the profile can be considered to be their characteristic features (Loiko et al., 2015).

In laboratory experiments, 10 soil horizons were studied (Fig. 2). These horizons characterize the entire range of the properties of the considered soils. The mollic horizon (profile L2) and parent material with and without carbonates (profile L1) were selected from the Luchanovo site (L). The albic and argic horizons (profile Bg2) and argic horizon (profile Bg1) were selected from the Bogashevo site (Bg). The umbric and albic horizons (profile Bs1), the argic horizon and the lower part of the mollic horizon of profile Bs2 (residual A) were selected from the Basandayka site (Bs). A total of 30 undisturbed soil monoliths were collected from soil pits in cylindrical experimental columns $15 \mathrm{~cm}$ high and $8 \mathrm{~cm}$ in diameter (Table A1). The monoliths from each horizon were sampled in triplicate. In the case of the sampling of endopedons, epipedons were removed. The soils were sampled by vertically driving the column to a depth of $15 \mathrm{~cm}$. To prevent soil from falling out of the core, its ends were wrapped with a net with a mesh diameter of $0.1 \mathrm{~mm}$. In this form, the columns were transported to the laboratory. Additionally, a sample was taken for analysis of the chemical and physical soil properties from each horizon.

\subsection{Analytical methods}

A number of physical and chemical properties of the soil horizons used in the experiments were analyzed. The samples were air-dried at $25^{\circ} \mathrm{C}$ for 1 week, mixed, grounded and sieved to $<1 \mathrm{~mm}$, and debris was removed prior to chemical and physical analysis. Soil pH was measured by potentiometry in the supernatant suspension of soil and water in a ratio of 1:5 (ISO 10390:2005, 2005). Organic carbon content (OC) was analysed by the Tyurin titrimetric method of wet oxidation (Vorobyova, 2006), which is analogous to the Walkey-Blake international method. Base saturation (BS) was determined by the method of $\mathrm{BaCl}_{2}$-TEA extractable acidity (Soil Survey Staff, 2014) and $1 \mathrm{~N}$ $\mathrm{NaCl}$ extractable bases $\left(\mathrm{Ca}^{2+}\right.$ and $\left.\mathrm{Mg}^{2}\right)$, measured by EDTA titration (Vorobyova, 2006). $\mathrm{H}^{+}$and $\mathrm{Al}^{3+}$ cations, extractable by $1 \mathrm{~N}$ $\mathrm{KCl}$, were determined using the method described by Sokolov (Vorobyova, 2006). In the $C$ horizon samples, the content of carbonates was also measured according to the complexometric method proposed by Kudrin (Vorobyova, 2006).

The following physical parameters of the soil samples were determined according to standard methods (Vadyunina and Korchagin, 1986): gravimetric soil moisture (SM), gravimetric mini- 
Table 1

Chemical properties of the studied soil horizons

\begin{tabular}{|c|c|c|c|c|c|c|c|c|c|c|c|}
\hline \multirow[t]{2}{*}{ Site } & \multirow[t]{2}{*}{ Soil } & \multirow[t]{2}{*}{ Horizon } & \multirow{2}{*}{$\begin{array}{l}\text { Depth } \\
\mathrm{cm}\end{array}$} & $\mathrm{Ca}^{2+}$ & $\mathrm{Mg}^{2+}$ & $\mathrm{H}^{+}$ & $\mathrm{Al}^{3+}$ & Acidity & \multirow{2}{*}{$\begin{array}{l}\mathrm{BS}^{1} \\
\%\end{array}$} & \multirow[t]{2}{*}{$\mathrm{pH}$} & \multirow{2}{*}{$\begin{array}{l}\mathrm{OC}^{2} \\
\%\end{array}$} \\
\hline & & & & \multicolumn{5}{|c|}{$\mathrm{cmol}_{\mathrm{c}} \mathrm{kg}^{-1}$} & & & \\
\hline L1 & $\begin{array}{l}\text { Luvic Greyzemic Phaeozems (Episiltic, } \\
\text { Endoloamic) }\end{array}$ & $\mathrm{Bc}$ & $120-130$ & 22.0 & 4.4 & 0.3 & 6.2 & 2.4 & 91.7 & 6.1 & 0.1 \\
\hline L1 & $\begin{array}{l}\text { Luvic Greyzemic Phaeozems (Episiltic, } \\
\text { Endoloamic) }\end{array}$ & Cca & $167-177$ & 33.2 & 6.4 & - & - & - & 100.0 & 7.5 & 0.04 \\
\hline L2 & $\begin{array}{l}\text { Endoluvic Endostagnic Phaeozems (Endoalbic, } \\
\text { Amphisiltic, Endoclayic }\end{array}$ & A & $0-10$ & 32.4 & 6.2 & 0.4 & 0.7 & 8.6 & 81.9 & 5.5 & 4.3 \\
\hline Bg1 & $\begin{array}{l}\text { Amphiluvic Phaeozems (Epialbic, Episiltic, } \\
\text { Endoloamic) }\end{array}$ & Bt & $67-77$ & 23.6 & 1.0 & 0.62 & 14.22 & 3.83 & 86.5 & 6.2 & 0.5 \\
\hline Bg2 & Albic Luvisols (Episiltic, Endoloamic) & E & $36-46$ & 12.2 & 9.4 & 0.3 & 23.4 & 7.5 & 74.2 & 5.8 & 1.8 \\
\hline Bg2 & Albic Luvisols (Episiltic, Endoloamic) & Bt & $90-100$ & 17.6 & 1.0 & 0.3 & 24.5 & 4.1 & 81.8 & 5.9 & 0.4 \\
\hline Bs1 & Albic Luvisol (Episiltic, Endoclayic, Endocutanic) & A & $0-10$ & 23.0 & 3.8 & 0.7 & 12.1 & 12.0 & 69.1 & 5.6 & 2.9 \\
\hline Bs1 & Albic Luvisol (Episiltic, Endoclayic, Endocutanic) & E & $30-40$ & 16.2 & 0.6 & 0.4 & 86.3 & 8.2 & 67.3 & 6.1 & 1.0 \\
\hline Bs2 & $\begin{array}{l}\text { Katoluvic Greyzemic Katostagnic Phaeozem } \\
\text { (Epiloamic, Endoclayic) }\end{array}$ & A & $30-40$ & 22.2 & 2.4 & 0.44 & 6.21 & 8.33 & 74.7 & 5.7 & 2.1 \\
\hline Bs2 & $\begin{array}{l}\text { Katoluvic Greyzemic Katostagnic Phaeozem } \\
\text { (Epiloamic, Endoclayic) }\end{array}$ & $\mathrm{Bt}$ & $75-85$ & 25.8 & 3.8 & 0.6 & 4.7 & 4.1 & 88.0 & 5.7 & 0.7 \\
\hline
\end{tabular}

${ }^{1}$ Base saturation; ${ }^{2}$ organic carbon.

Table 2

Physical properties and soil texture of the studied soil horizons

\begin{tabular}{|c|c|c|c|c|c|c|c|c|c|c|c|c|}
\hline \multirow[t]{3}{*}{ Site } & \multirow[t]{3}{*}{ Soil } & \multirow[t]{3}{*}{ Horizon } & \multirow{3}{*}{$\begin{array}{l}\text { Depth } \\
\mathrm{cm}\end{array}$} & \multirow{3}{*}{$\begin{array}{l}\mathrm{BD}^{1} \\
\mathrm{~g} \mathrm{~cm}^{-3}\end{array}$} & \multirow[t]{2}{*}{$\mathrm{SM}^{2}$} & \multirow[t]{3}{*}{$\mathrm{MC}^{3}$} & \multicolumn{6}{|c|}{ Particle size fractions, $\mu \mathrm{m}$} \\
\hline & & & & & & & $<1$ & $1-5$ & $5-10$ & $10-50$ & $50-250$ & $250-1000$ \\
\hline & & & & & $\%$ & & & & & & & \\
\hline L1 & $\begin{array}{l}\text { Luvic Greyzemic Phaeozems (Episiltic, } \\
\text { Endoloamic) }\end{array}$ & $\mathrm{Bc}$ & $120-130$ & 1.4 & 10.9 & 30.3 & 19.2 & 7.0 & 7.1 & 48.7 & 17.9 & 0.1 \\
\hline L1 & $\begin{array}{l}\text { Luvic Greyzemic Phaeozems (Episiltic, } \\
\text { Endoloamic) }\end{array}$ & Cca & $167-177$ & 1.3 & 9.7 & 29.0 & 21.1 & 6.7 & 7.7 & 46.9 & 17.4 & 0.2 \\
\hline L2 & $\begin{array}{l}\text { Endoluvic Endostagnic Phaeozems (Endoalbic, } \\
\text { Amphisiltic, Endoclayic }\end{array}$ & $\mathrm{A}$ & $0-10$ & 0.9 & 19.6 & 46.0 & 15.6 & 10.6 & 8.1 & 44.6 & 20.6 & 0.5 \\
\hline Bg1 & $\begin{array}{l}\text { Amphiluvic Phaeozems (Epialbic, Episiltic, } \\
\text { Endoloamic) }\end{array}$ & $\mathrm{Bt}$ & $67-77$ & 1.4 & 12.1 & 22.2 & 34.0 & 6.5 & 6.7 & 38.9 & 13.9 & 0.0 \\
\hline Bg2 & Albic Luvisols (Episiltic, Endoloamic) & E & $36-46$ & 1.3 & 16.6 & 32.2 & 11.0 & 11.2 & 10.5 & 47.4 & 19.2 & 0.6 \\
\hline Bg2 & Albic Luvisols (Episiltic, Endoloamic) & $\mathrm{Bt}$ & $90-100$ & 1.7 & 15.7 & 27.4 & 24.9 & 7.8 & 8.0 & 41.1 & 18.2 & 0.0 \\
\hline Bs1 & Albic Luvisol (Episiltic, Endoclayic, Endocutanic) & A & $0-10$ & 0.6 & 38.7 & 80.1 & 9.2 & 13.1 & 10.0 & 56.3 & 11.3 & 0.2 \\
\hline Bs1 & Albic Luvisol (Episiltic, Endoclayic, Endocutanic) & E & $30-40$ & 1.4 & 20.3 & 31.7 & 13.5 & 13.0 & 10.9 & 51.3 & 11.2 & 0.1 \\
\hline Bs2 & $\begin{array}{l}\text { Katoluvic Greyzemic Katostagnic Phaeozem } \\
\text { (Epiloamic, Endoclayic) }\end{array}$ & A & $30-40$ & 1.3 & 26.5 & 37.0 & 25.7 & 10.6 & 10.0 & 39.6 & 13.8 & 0.2 \\
\hline Bs2 & $\begin{array}{l}\text { Katoluvic Greyzemic Katostagnic Phaeozem } \\
\text { (Epiloamic, Endoclayic) }\end{array}$ & $\mathrm{Bt}$ & $75-85$ & 1.4 & 23.3 & 34.5 & 31.9 & 7.9 & 8.8 & 38.9 & 12.4 & 0.1 \\
\hline
\end{tabular}

${ }^{1}$ Bulk density; ${ }^{2}$ soil moisture; ${ }^{3}$ minimum moisture-holding capacity.

mum moisture-holding capacity (MC) and bulk density (BD). Particle size analysis was conducted using the pipette method with the pyrophosphate procedure used for soil preparation. Soil size fractions were defined as clay $(<0.001 \mathrm{~mm})$, fine silt $(0.001-0.005$ $\mathrm{mm})$, medium silt $(0.005-0.01 \mathrm{~mm})$, coarse silt $(0.01-0.05 \mathrm{~mm})$, fine sand (0.05-0.25 mm) and medium and coarse sand $(0.25-$ $1.00 \mathrm{~mm}$ ) according to the East European texture classification system (Kachinskiy, 1956). 
The concentration of Pt in the studied soil samples was determined using ICP-MS at the accredited Chemical Analytical Center "PLASMA" (Tomsk, Russia) according to MVI 001-XMC2007 (PLAZMA 2015). The prepared soil sample of $0.1 \mathrm{~g}$ was subjected to ashing at $450^{\circ} \mathrm{C}$ and digested in a concentrated HF$\mathrm{HNO}_{3}-\mathrm{HClO}_{4}$ mixture. The concentrations of $\mathrm{Pt}$ of the digested solution were determined by an EIAN DRC-e spectrometer (PerkinElmer, USA). QA/QC included reagent blanks, analytical duplicates and analysis of the state standard reference samples. The relative error was not higher than $20 \%$. The method detection limit (MDL) for Pt was $0.01 \mathrm{mg} \mathrm{kg}^{-1}$. In this study, a Pt concentration below the MDL was taken as half of one (Johnson et al., 2011) and equal to $0.005 \mathrm{mg} \mathrm{kg}^{-1}$. This value is several orders of magnitude lower than the upper continental crust content of metal $\left(0.5 \mathrm{mg} \mathrm{kg}^{-1}\right)$ (Rudnick, Gao, 2003) or world soil average (0.02 $\mathrm{mg} \mathrm{kg}^{-1}$ ) (Kabata-Pendias, 2011), but it is similar to the estimations by Greenwood and Earnshaw (1989). It should be noted that the direct determination of Pt in various environmental objects is often difficult due to the low concentrations (Komendova, 2020). Previous studies (Kulizhsky et al., 2013, 2017) have shown that background Pt content in natural soils of sites under consideration are close or below the detection limit of the chosen method. At the same time, the concentration of Pt in the suspensions used for the experiments was significantly higher; therefore, its accumulation in the columns could be easily tracked, and we could assume that all the detected Pt in the columns is related to its migration from the suspension in the form of PtNPs.

\subsection{PtNP suspension}

PtNPs were obtained by laser ablation in distilled water from high-purity (99.97\%) platinum bars, as described in (Kulizhskiy et al., 2017). The characteristics of NPs were verified by TEM (Phillips CM-12, France), dynamic light scattering (Zetasizer Nano ZS, USA) and BET (TriStar 3000, USA). The size of PtNPs $(\Delta 50)$ was $5 \mathrm{~nm}$, and the specific surface (S) area was $36 \mathrm{~m}^{2} \mathrm{~g}^{-1}$. The concentration of PtNPs in suspension was $10 \mathrm{mg}$ $\mathrm{L}^{-1}$. Deionized water (Milli-Q) was used as a dispersion medium.

\subsection{Column experiments}

In the laboratory, the experimental columns with soil were placed in a container with a suspension of nanoparticles with at a concentration of $10 \mathrm{mg} \mathrm{L}^{-1}$ at a depth of $0.5 \mathrm{~cm}$ for a week. The lower part of the column, which was immersed in the suspension $(0.5 \mathrm{~cm})$, was cut off during sampling. To create a moisture gradient in the columns during the experiment, their tops remained open, and the container with the suspension was isolated from evaporation. Subsequently, the total content of platinum in the samples from the upper and lower parts of the columns was determined. These samples were $2.5 \mathrm{~cm}$ thick. For this, the edge parts of the soil monoliths were cut off and transferred to ICP-MS. The total platinum concentrations at the ends of the columns allowed us to calculate the coefficient of differentiation of the distribution of platinum in the column $\left(K_{P t N P S}\right)$, given by the following equation:
$K_{P t N P s}=\frac{C_{\text {top }} \times 100 \%}{C_{\text {bottom }}}$

where $\mathrm{C}_{\text {top }}$ is the Pt concentration in the upper part of the column, and $\mathrm{C}_{\text {bottom }}$ is the Pt concentration in the deeper part of the column.

\subsection{Data analysis}

Multivariate statistical analysis and data visualization were conducted using the STATISTICA 12 software package. The analysis of histograms and the Kolmogorov-Smirnov test were utilized to examine the normality of the studied parameters, and non-normal variables were standardized to a z-score. The homogeneity of variance was tested using Levene's test. Hierarchical cluster analysis (HCA) was used to group the soil columns based on the absorption rate of PtNPs according to Ward's method; the measure of similarity used 1-Pearson's $r$, and the results were reported in the form of a dendrogram. The critical level of amalgamation for a set of 30 samples was 0.639 at $p<0.05$. Differences between soil columns were determined using main effects one-way ANOVA followed by a post hoc test (LSD test). Pearson correlation coefficients were calculated to determine the relationships between soil properties and PtNP concentrations.

\section{Results}

\subsection{Properties of studied horizons}

The data on the selected chemical and physical properties of studied horizons are presented in Tables 1 and 2. It is clearly visible that various horizons show differences in the studied parameters.

The $\mathrm{pH}$ values increased from 5.5-5.7 in A horizons to 5.86.1 in $\mathrm{E}$ horizons and 5.7-6.2 in Bt and $\mathrm{BC}$ horizons. The highest $\mathrm{pH}$ was characteristic of the Cca horizon, which is clearly due to the presence of carbonates (5.4\%). The content of organic carbon decreased from 2.1-4.3 in A horizons to 1.0-1.8 in E horizons, 0.4$0.7 \%$ in Bt horizons and $0.0-0.1 \%$ in Bc and Cca horizons. The variation of acidity and base saturation values were rather characteristic for soils with eluvial-illuvial differentiation of the profile, when the highest BS decreases in the following row $\mathrm{Cca}-\mathrm{Bc}$ - Bt - A - E horizons, and acidity shows a reverse trend, respectively. Both soil moisture and minimum moisture-holding capacity were highest in the upper part of the soil profile and decreased with depth. The bulk density varied from a minimum value of 0.6 $\mathrm{g} \mathrm{cm}^{-3}$ in the A horizon of Albic Luvisol from the Basandayka site to a maximum value of $1.7 \mathrm{~g} \mathrm{~cm}^{-3}$ in the Bt horizon of Albic Luvisol from the Bogashevo site. The variations in the content of clay fraction in the studied samples showed very similar trends, with the bulk density reaching the maximum and minimum values in the horizons of Albic Luvisols with pronounced eluvial-illuvial differentiation of the profile up to $34.0 \%$ in Bt and $9.2 \%$ in $\mathrm{A}$, as well as $13.5 \%$ in E. In general, discussion regarding the differences in properties between individual soil profiles or types is difficult; however, we discuss the most representative horizons of the most common components of the soil cover. 


\subsection{PtNP transfer with capillary rise}

The results obtained during the experiments are available in Appendix and in Fig. 3. The obtained results showed that the maximum concentrations of $\mathrm{Pt}$ in the bottom parts of the columns decreased in the following raw $\mathrm{A}>\mathrm{E}>\mathrm{Bc}>\mathrm{Cca}>\mathrm{Bt}$ horizons. It is important to note that concentrations of $\mathrm{Pt}$ in the bottom part of the columns with the $\mathrm{A}, \mathrm{E}$ and $\mathrm{Bc}$ horizons were several magnitudes higher than in the Bt horizons, except for the residual humus horizon of the Bs2 profile (Katoluvic Greyzemic Katostagnic Phaeozem).

The results for the PtNP concentrations in the upper part of the column were rather different. The concentration in the upper parts of the Bt horizons were comparable or even higher than in the E and Bc horizons, except for the Bt of the Bs2 profile (Katoluvic Greyzemic Katostagnic Phaeozem) from the Basandayka site. The highest values of Pt content were observed in the A horizon of the L2 profile (Endoluvic Endostagnic Phaeozems) representing the Luchanovo site. At the same time, this result requires further examination since one of three columns showed values two magnitudes higher than all other columns in the experiment, and therefore it should likely not be included in discussion due to the low degree of confidence. In total, most of the columns for the individual horizons showed a low degree of variability. The absence of PtNP accumulation in the upper parts of the columns representing the Cca horizon of the L1 profile (Luvic Greyzemic Phaeozems) from the Luchanovo site is also worth mentioning.
Only one of three individual columns showed PtNP concentrations in its upper part higher than the detection limits.

The $\mathrm{K}_{\mathrm{PtNPs}}$ values were rather high for the Bt horizons in particular, as well as for both the Bt and A horizons of the soils representing the Basandayka site. The reasons for the high variability of the $\mathrm{K}_{\mathrm{PtNPs}}$ values in the A horizon of the Bs1 and Bs2 profiles representing the Basandayka site are discussed in the paragraph above.

\subsection{Relationships between properties and soil type and PtNP mobility}

The results of the correlation analysis demonstrating the relationship between PtNP concentrations and the properties of the studied samples are presented in Table 3. For the concentration of PtNPs in the bottom part of the columns, one can see a significant $(\mathrm{p}<0.05)$ strong positive correlation with the content of organic carbon (0.74), a moderate positive correlation with the content of medium and coarse sand (0.54), a weak positive correlation with the acidity (0.50) and a minimum moisture-holding capacity $(0.50)$, as well as contents of fine $(0.46)$ and coarse silt $(0.44)$ and a negative moderate correlation with bulk density (-0.68) and content of clay fraction (-0.58). The concentrations of PtNPs in the upper parts of the columns showed significant $(\mathrm{p}<0.05)$ weak and moderate positive correlations with soil moisture ( 0.42$)$, coarse silt content ( 0.38 ) and minimum moisture-holding capacity (0.51), as well as weak negative cor-
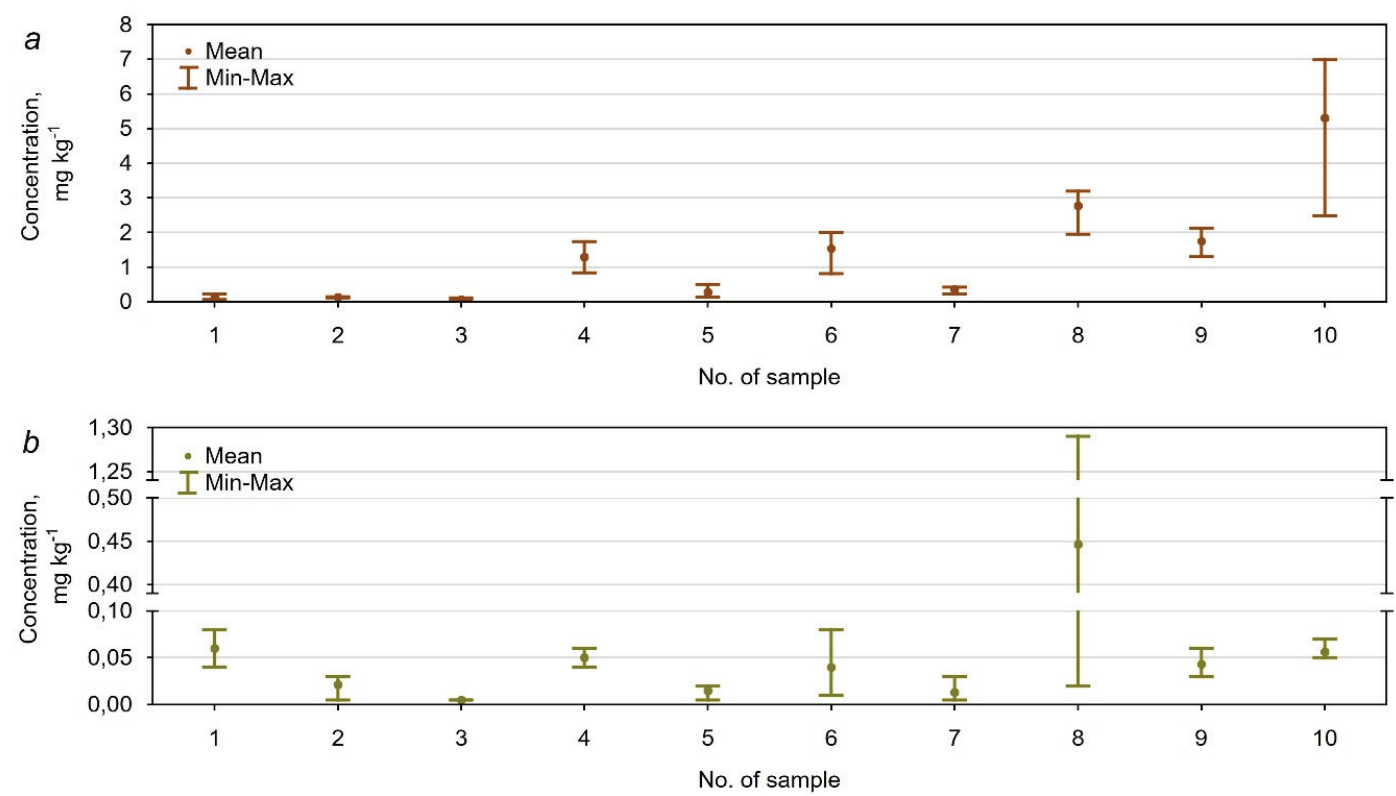

$c$

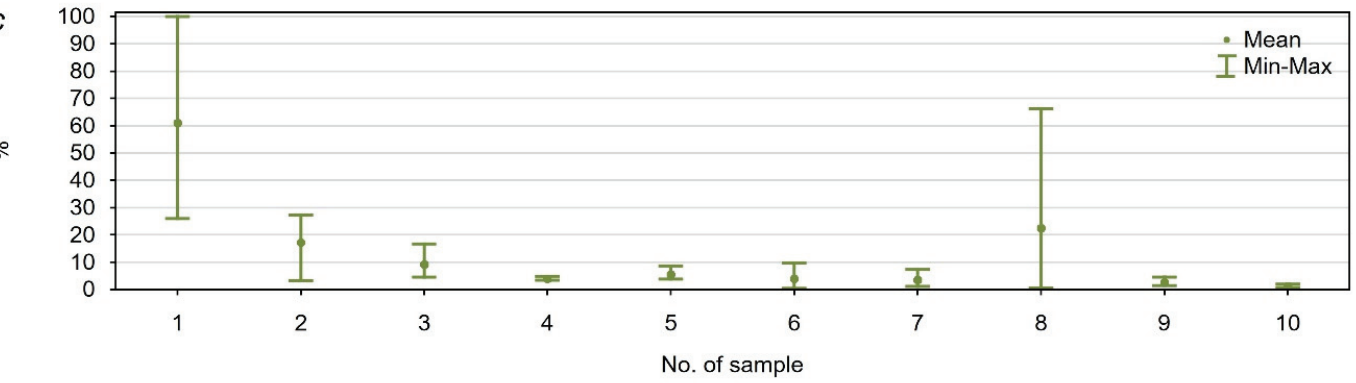

Fig. 3. Means plots showing the distribution of (a) Pt concentration in the lower part of soil columns; (b) Pt concentration in the upper part of soil columns; (c) differentiation coefficient (KPtNPs). 
relations with bulk density $(-0.44)$. The values of the KPtNP coefficient showed significant $(\mathrm{p}<0.05)$ moderate positive correlations with $\mathrm{H}^{+}(0.46)$ and clay (0.39).

To highlight the differences in PtNP concentrations between the soil columns, the significance of soil type and horizons was assessed using one-way ANOVA (Table 4). According to the multivariate Wilks lambda criterion, the soil type and soil horizon were highly significant for PtNP mobility $(\mathrm{p}<0.0005)$. Significant differences depending on the soil type and soil horizon were found only for the PtNP content in the bottom layer of the column (Table 3). The LSD test revealed that the L2 profile (Endoluvic Greyzemic Phaeozems) exhibit the highest absorption capacity in relation to PtNPs in comparison with all other soils. In addition, significant differences were identified between the Bs1 (Albic Luvisol) and Bs2 (Katoluvic Greyzemic Katostagnic Phaeozem) profiles. Significant differences in the PtNP content in the bottom part of the column were observed between the Bt horizons and all other horizons except $\mathrm{BC}$, as well as between the $\mathrm{A}, \mathrm{E}$ and Cca horizons.
The results of the hierarchical cluster analysis (HCA) are presented in Fig. 4. The hierarchical dendrogram shows four clusters, although their interpretation is not always exact. The first cluster mainly unites samples from the E horizon of the Bs1 profile and the $\mathrm{BC}$ horizon of the L1 profile, the A horizon of the L2 profile and the A horizon of the Bs1 profile and the E horizon of the Bg2 profile. The second cluster is represented by different soils; it is almost entirely composed of the Cca horizon of Luvic Greyzemic Phaeozems. The third cluster unites the Bt horizon of the Bg1 (Amphiluvic Phaeozems) and Bg2 (Albic Luvisols) profiles. The fourth one mainly refers to the Bt and A horizons of the Bs2 profile (Katoluvic Greyzemic Katostagnic Phaeozem). Two large clusters that unite the first and second clusters and third, fourth and fifths clusters, respectively, cannot be indicated, as their linkage appears above the critical level of amalgamation; however, they give indirect evidence of the relationships between the A and E horizons on the one hand and the Bt, Cca and residual A horizons on the other.

Table 3

Pearson correlation coefficients between platinum nanoparticle (PtNP) concentrations and properties of soils

\begin{tabular}{|c|c|c|c|c|c|}
\hline \multirow{3}{*}{$\begin{array}{l}\text { Variable } \\
\mathrm{pH}\end{array}$} & \multicolumn{2}{|c|}{ Concentration, $\mathrm{mg} \mathrm{kg}^{-1}$} & \multirow[t]{2}{*}{$\mathrm{K}_{\mathrm{PtNPs}}$} & \multirow{4}{*}{\multicolumn{2}{|c|}{ Color map }} \\
\hline & \multirow{2}{*}{$\begin{array}{l}\text { Bottom } \\
-0.34\end{array}$} & Top & & & \\
\hline & & -0.16 & -0.05 & & \\
\hline Soil Organic Carbon & 0.74 & 0.25 & -0.08 & & \\
\hline $\mathrm{Ca}^{2+}$ & 0.25 & -0.01 & 0.02 & & 1.0 \\
\hline $\mathrm{Mg}^{2+}$ & 0.29 & 0.003 & -0.33 & & 0.8 \\
\hline $\mathrm{H}^{+}$ & 0.09 & 0.31 & 0.46 & & 0.6 \\
\hline $\mathrm{Al}^{3+}$ & -0.01 & -0.03 & -0.103 & & 0.4 \\
\hline Acidity & 0.50 & 0.35 & 0.01 & & 0.2 \\
\hline Base Saturation & -0.26 & -0.25 & 0.003 & & 0.0 \\
\hline Soil Moisture & 0.26 & 0.42 & 0.03 & & -0.2 \\
\hline Minimum Moisture-Holding Capacity & 0.50 & 0.51 & -0.03 & & -0.4 \\
\hline Bulk density & -0.68 & -0.44 & -0.01 & & -0.6 \\
\hline Clay & -0.58 & -0.28 & 0.39 & & -0.8 \\
\hline Fine Silt & 0.46 & 0.29 & -0.19 & & -1.0 \\
\hline Medium Silt & 0.10 & 0.15 & -0.26 & & \\
\hline Coarse Silt & 0.44 & 0.38 & -0.23 & & \\
\hline Fine Sand & 0.28 & -0.22 & -0.30 & & \\
\hline Medium and Coarse Sand & 0.54 & 0.05 & -0.27 & bold & $\mathrm{p}<\mathrm{c}$ \\
\hline
\end{tabular}

Table 4

Results of main effects one-way ANOVA for studied soils

\begin{tabular}{|c|c|c|c|c|c|c|c|c|c|c|c|c|c|c|c|}
\hline \multirow{2}{*}{ Effect $^{1}$} & \multicolumn{5}{|l|}{$\mathrm{C}_{\text {bottom }}$} & \multicolumn{5}{|l|}{$\mathrm{C}_{\text {top }}$} & \multicolumn{5}{|l|}{$\mathrm{K}_{\mathrm{PtNPs}}$} \\
\hline & SS & DF & MS & $\mathrm{F}$ & $\mathrm{p}$ & SS & DF & MS & $\mathrm{F}$ & $\mathrm{p}$ & SS & $\mathrm{DF}$ & MS & $\mathbf{F}$ & $\mathbf{p}$ \\
\hline Horizon & 3.494 & 3 & 1.165 & 3.982 & 0.020 & 4.937 & 3 & 1.646 & 1.667 & 0.202 & 9.927 & 3 & 3.309 & 52.754 & 0.000 \\
\hline Soil & 11.381 & 2 & 5.690 & 19.459 & 0.000 & 3.836 & 2 & 1.918 & 1.943 & 0.166 & 0.383 & 2 & 0.191 & 3.052 & 0.067 \\
\hline Error & 6.726 & 23 & 0.292 & & & 22.702 & 23 & 0.987 & & & 1.443 & 23 & 0.063 & & \\
\hline
\end{tabular}

${ }^{1}$ Significant effects $(\mathrm{p}<0.05)$ are in bold. 


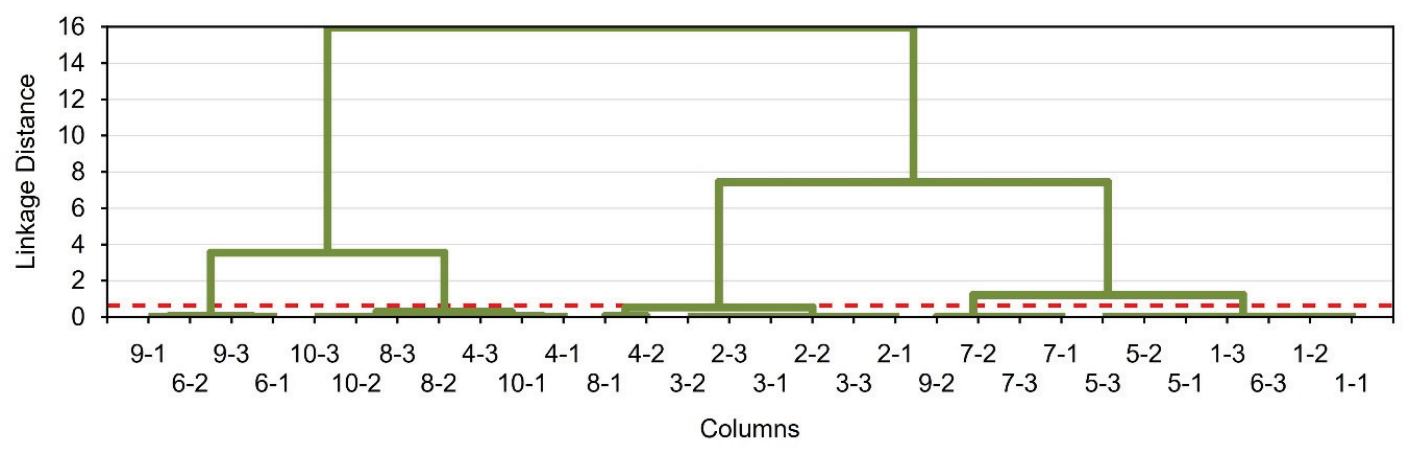

Fig. 4. Hierarchical dendrogram showing clustering of studied soil columns according to Pt concentrations using Ward's method of amalgamation and the 1- Pearson's $r$ distance as the distance measure. The dashed line in the dendrogram represents the critical level of amalgamation

\section{Discussion}

While discussing the obtained results, we should be precise in terms of conclusions since the experiments performed with the columns of natural soils, especially Phaeozems and Luvisols, are very heterogenous, unlike artifactual saturated porous media, which are typically used for studies of metallic NP transfer. Another important issue that significantly complicates the interpretation of the data is related to the absence of modeling in these experiments as it is very difficult to evaluate the input parameters. At the same time, the data obtained allow us to note several interesting probabilistic points. The ability to scale the revealed patterns allows us to understand the properties of soils in other regions, which are similar to the studied soils (Glina et al., 2013; Kobierski et al., 2015).

The physical properties of the soils had a noticeable effect on the capillary rise of PtNP colloids. The minimum moisture holding capacity of humus horizons is relatively high, and the soil density is the lowest among all horizons. This indirectly indicates a high rate of capillary pores. These pores retain moisture. Epipedons are often characterized by increased water holding capacity (Polyakov et al., 2020). Due to this, the epipedons not only easily absorb suspensions but also fix them, acting as sorption barriers not only for dissolved forms, but also for nanoparticles (colloids) (Kulizhskiy et al., 2013, 2017). A higher intensity of Pt transfer with capillary rise was observed in the A and E horizons, while it was lower in the Bt and Cca horizons. The A and E horizons are characterized by the highest content of organic carbon, which significantly increases their potential for the sorption of PtNPs (Philippe, Schaumann, 2014; Reith, Cornelis, 2017; Komendová et al., 2019). A significant limiting factor for the migration of highly dispersed matter is the presence of carbonates in the horizon. The results of various studies concerning the transport of metallic NPs in the saturated porous media showed that their mobility also decreases with the increase in the content of carbonates (Laumann et al., 2013; Adrian et al., 2019).

PtNPs in Phaeozems and Luvisols are able to move not only with the gravitational current of water, but also under the action of capillary forces in any direction relative to the gravity vector. The volume and range of transfer of highly dispersed material increases with decreasing density. This fact is very important for the modeling of plant nutrition, since this effect provides NPs with the ability to move in any direction relative to the force of gravity, which can be important during their remobilization due to the flow of capillary water along the moisture gradient that is created around the root system (Ghestem et al., 2011).

The process of the transfer of colloids under the action of capillary phenomena was possible in almost all the studied horizons, but the transfer distances were rather limited. Apparently, in natural soils, this migration mechanism probably leads to the transfer of colloids in the illuvial horizons from magistral pores to pores of lower orders. It was also seen that different genetic horizons showed various intensities of PtNP migration with capillary rise with respect to their chemical and physical properties (Kodešova et al., 2011). For example, the Bt horizon of the Katoluvic Greyzemic Katostagnic Phaeozem (Epiloamic, Endoclayic) of the local depression within the aspen-fir taiga is worth mentioning. In the experiments with columns from this horizon, the PtNPs managed to transfer only into the lower part of the column, while the concentrations of Pt in the upper part for all three replications were lower than the detection limits. However, it is possible to suggest that the degree of clogging of the pore space in the textural horizon of this soil is so great that the fine particles are practically unable to move through themselves, although it can also be explained by the peculiarity of the experimental columns, in which there is a slight compaction of the soil. Under such conditions, the residual A horizon partly plays the role of illuvial, which is supported by the results of cluster analysis.

The revealed mechanism of migration of PtNPs through capillaries suggests that a similar transfer of colloids of other chemical compounds is possible. This has two important implications. (1) In soil horizons without macropores, colloidal particles can migrate with both lateral and vertical flows of capillary water. Transfer of colloids can be expected even in "warm” permafrost, where, as is known, capillary moisture is in an unfrozen state (Ming et al., 2020; Qiu et al., 2020) and migrates to the freezing front. The revealed process can explain the accumulation of dissolved and colloidal forms of elements in dispersed ice below the active layer in the peat deposit of Cryic Histisols (Lim et al., 2021). The second consequence is associated with the recently described mechanism for the uptake of natural colloidal phosphorus by plants (Montalvo et al., 2015; Bollyn et al., 2017). 
This indicates that colloidal particles entering the rhizosphere through capillaries play an important role in plant nutrition even in the absence of macropores.

\section{Conclusions}

The present work showed that in all investigated soil horizons of Phaeozems and Luvisols, PtNP suspensions relocate by water flow to soil capillaries despite the gravity gradient. At short distances (centimeters), soil organic carbon, the minimum moisture-holding capacity, acidity sand contribute to a greater transfer of PtNPs. Sand particles form pores between themselves, which have a large cross-section that does not contribute to the development of long-range capillary transfer but contains a large volume of suspension. Bulk density and clay limit the absorption of the PtNPs. Clay increases the packing density by reducing the number of active capillary pores. At longer distances, measured in the first tens of $\mathrm{cm}$, the relocation of PtNPs is regulated by the minimum moisture-holding capacity; the higher its value, the more PtNPs are relocated. This property depends on the volume of capillaries capable of retaining water. Long-distance transport is favored by coarse silt; these particles create capillaries with an optimal cross-section. The opposite effect causes an increase in the bulk density, which prevents the relocation of PtNPs. The coefficient of KPtNPs, which shows the percentage of nanoparticles displaced to the top of the column, positively correlates with the amount of $\mathrm{H}^{+}$in the exchange state.

The transfer of water under the action of capillary forces plays an essential role in soils, especially when water is pulled into the rhizosphere in the dry season. Plants take up PtNPs (Astafurova et al., 2015; Ahmed et al., 2021), which means that the established capillary transfer will enhance the uptake of PtNPs by the roots. The least active nanoparticles move in the capillary pores of the carbonate horizons. For dense soil horizons without macropores, capillary pores are the only pathways for water movement. The experiments carried out show the possibility of cutan formation in fine pores due to the transfer of colloids under the action of capillary forces.

\section{Acknowledgments}

This research was supported by the Russian Science Foundation (grant No. 19-16-00049).

\section{References}

Abakumov, E.V., Loyko, S.V., Istigechev, G.I., Kulemzina, A.I., Lashchinskiy, N.N., Andronov, E.E., Lapidus, A.L., 2020. Soils of Chernevaya taiga of western Siberia - morphology, agrochemical features, microbiome. Sel'skokhozyaistvennaya Biologiya - Agricultural Biology 55(5), 1018-1039. https://doi:10.15389/agrobiology.2020.5.1018eng

Abbas, Q., Yousaf, B., Amina Ali, M.U., Munir, M.A.M., El-Naggar, A., Rinklebe. J., Naushad, M., 2020. Transformation pathways and fate of engineered nanoparticles (ENPs) in distinct interactive environmental compartments: A review. Environment International 138, 105646. https://doi:10.1016/j.envint.2020.105646
Adrian, Y.F., Schneidewind, U., Scott, A.B., Šimůnek, J., Klumpp, E., Azzam, R., 2019. Transport and retention of engineered silver nanoparticles in carbonate-rich sediments in the presence and absence of soil organic matter. Environmental Pollution 255(1), 113124. https://doi. org/10.1016/j.envpol.2019.113124

Ahmed, B., Rizvi, A., Ali, K., Lee, J., Zaidi, A., Khan, M.S., Musarrat, J., 2021. Nanoparticles in the soil-plant system: a review. Environmental Chemistry Letters 19, 1545-1609. https://doi.org/10.1007/s10311-02001138-y

Alex, S., Tiwari, A., 2015. Functionalized gold nanoparticles: synthesis, properties and applications - a review. Journal of Nanoscience and Nanotechnology 15(3), 1869-1894. https://doi.org/10.1166/ jnn.2015.9718

Astafurova, T., Zotikova, A., Morgalev, Y., Verkhoturova, G., Postovalova, V., Kulizhskiy, S., Mikhailova, S., 2015. Effect of platinum nanoparticles on morphological parameters of spring wheat seedlings in a substrate-plant system. IOP Conference Series: Materials Science and Engineering 98(1), 012004. https://doi.org/10.1088/1757899X/98/1/012004

Bakshi, S., He, Z.L., Harris, W.G., 2015. Natural Nanoparticles: Implications for Environment and Human Health - Critical Reviews. Environmental Science and Technology 45(8), 861-904. https://doi:10.108 0/10643389.2014.921975

Ben-Moshe, T., Dror, I., Berkowitz, B., 2010. Transport of metal oxide nanoparticles in saturated porous media. Chemosphere 81(3), 387-393. https://doi.org/10.1016/j.chemosphere.2010.07.007

Bollyn, J., Faes, J., Fritzsche, A., Smolders, E., 2017. Colloidal-Bound Polyphosphates and Organic Phosphates Are Bioavailable: A Nutrient Solution Study. Journal of Agricultural and Food Chemistry 65, 6762-6770. https://doi.org/10.1021/acs.jafc.7b01483

Boxall, A., Chaudhry, Q., Sinclair, C., Jones, A., Aitken, R., Jefferson, B., Watts, C., 2007. Current and future predicted environmental exposure to engineered nanoparticles. Central Science Laboratory, York, UK. http://randd.defra.gov.uk/Document.aspx?Document=CB01098_ 6270_FRP.pdf

Braun, A., Klumpp, E., Azzam, R., Neukum, C., 2015. Transport and deposition of stabilized engineered silver nanoparticles in water saturated loamy sand and silty loam. Science of The Total Environment 535, 102-112. https://doi.org/10.1016/j.scitotenv.2014.12.023

Bundschuh, M., Filser, J., Luderwald, S., McKee, M. S., Metreveli, G., Schaumann, G. E., Schulz, R., Wagner, S., 2018. Nanoparticles in the environment: where do we come from, where do we go to? Environmental Sciences Europe 30(36), 1-17. https://doi.org/10.1186/s12302018-0132-6

Campbell, G., Reith, F., Etschmann, B., Brugger, J., Southam, G., 2015. Surface transformations of platinum grains from Fifield New South Wales, Australia. American Mineralogist 100(8), 1236-1243. https:// doi.org/10.2138/am-2015-4905

Cornelis, G., Hund-Rinke, K., Kuhlbusch, T., van den Brink, N., Nickel, C., 2014. Fate and bioavailability of engineered nanoparticles in soils: a review. Critical Reviews in Environmental Science and Technology 44, 2720-2764. https://doi.org/10.1080/10643389.2013.829767

Cornelis, G., Pang, L.P., Doolette, C., Kirby, J.K., McLaughlin, M.J., 2013. Transport of silver nanoparticles in saturated columns of natural soils. Science of the Total Environment 463, 120-130. https://doi. org/10.1016/j.scitotenv.2013.05.089

Dror I., Yaron B., Berkowitz B., 2015. Abiotic soil changes induced by engineered nanomaterials: A critical review. Journal of Contaminant Hydrology 181, 3-16. https://doi.org/10.1016/j.jconhyd.2015.04.004

Gestel, C.A., Kool, P.L., Diez, Ortiz, M., 2010. Metal-based nanoparticles in soil: New research themes should not ignore old rules and theories. Comments on the paper by $\mathrm{Hu}$ et al. (2010) 'Toxicological effects of $\mathrm{TiO}_{2}$ and $\mathrm{ZnO}$ nanoparticles in soil on earthworm Eisenia fetida.' Soil Biology \& Biochemistry 42, 586-591. Soil Biology and Biochemistry 42(10), 1892-1893. https://doi.org/10.1016/j.soilbio.2010.07.009 
Ghestem, M., Sidle, R.C., Stokes, A., 2011. The influence of plant root systems on subsurface flow: implications for slope stability. Bioscience 61(11), 869-879. https://doi.org/10.1525/bio.2011.61.11.6

Glina, B., Jezierski, P., Kabala, C., 2013. Physical and water properties of Albeluvisols in the Silesian Lowland (SW Poland). Soil Science Annual 64 (4), 123-129. https://doi.org/10.2478/ssa-2013-0019

Greenwood, N.N., Earnshaw, A., 2007. Chemistry of the Elements. Pergamon, Oxford.

Hansen, S., Heggelund, L. R., Revilla Besora, P., Mackevica, A., Boldrin, A., Baun, A., 2016. Nanoproducts - what is actually available to European consumers? Environmental Science: Nano 3, 169-180. https://doi. org/10.1039/C5EN00182J

He, J., Wang, D., Zhou, D., 2019. Transport and retention of silver nanoparticles in soil: Effects of input concentration, particle size and surface coating. Science of the Total Environment 648, 102-108. https://doi. org/10.1016/j.scitotenv.2018.08.136

Hough, R.M., Noble, R., Reich, M., 2011. Natural gold nanoparticles. Ore Geology Reviews 42(1), 55-61. https://doi.org/10.1016/j.oregeorev.2011.07.003

Hough, R.M., Noble, R.R.P., Hitchen, G.J., Hart, R., Reddy, S.M., Saunders, M., Clode, P., Vaughan, D., Lowe, J., Gray, D.J., Anand, R.R., Butt, C.R.M., Verrall, M., 2008. Naturally occurring gold nanoparticles and nanoplates. Geology 36, 571-574. https://doi.org/10.1130/G24749A.1

ISO 10390:2005. Soil quality. Determination of pH, 2005. https://www.iso. org/standard/40879.html.

IUSS Working Group WRB, 2015. World reference base of soil resources 2014, update 2015. International soil classification system for naming soils and creating legends for soil maps. World Soil Resources Reports no. 106. Rome: FAO.

Johnson, C.C., Demetriades, A., Locutura, J., Ottesen, R.T., 2011. Mapping the Chemical Environment of Urban Areas. John Wiley \& Sons Ltd., Chichester. https://doi.org/10.1002/9780470670071.

Kabata-Pendias, A., 2011. Trace Elements in Soils and Plants, fourth ed. CRC Press, Boca Raton. https://doi.org/10.1201/b10158.

Kachinskiy, N.A., 1956. Die mechanische Bodenanalyse und die Klassifikation der Boden nach ihrer mechanischen Zusammansetzung. Rapports au Sixieme Congres de la Science du Sol. Part B. Paris, 321-327.

Kobierski, M., Kondratowicz-Maciejewska, K., Kociniewska, K., 2015. Soil quality assessment of Phaeozems and Luvisols from the Kujawy region (central Poland). Soil Science Annual 66(3), 111-118. https://doi. org/10.1515/ssa-2015-0026

Kodešova, R., Jirku, V., Kodes, V., Muhlhanselova, M., Nikodem, A., Žigová, A., 2011. Soil structure and soil hydraulic properties of Haplic Luvisol used as arable land and grassland. Soil and Tillage Research 111(2), 154-161. https://doi.org/10.1016/j.still.2010.09.007

Komendova, R., 2020. Recent advances in the preconcentration and determination of platinum group metals in environmental and biological samples. TrAC Trends in Analytical Chemistry 122, 115708. https:// doi.org/10.1016/j.trac.2019.115708

Komendová, R., Žídek, J., Berka, M., Jemelková, M., Řezáčová, V., Conte, P., Kučerík, J., 2019. Small-sized platinum nanoparticles in soil organic matter: Influence on water holding capacity, evaporation and structural rigidity. Science of The Total Environment 694, 133822. https:// doi.org/10.1016/j.scitotenv.2019.133822

Korshunova, V.A., Charykova, M.V., 2019. Mobile Forms of Gold and Pathfinder Elements in Surface Sediments at the Novye Peski Gold Deposit and in the Piilola Prospecting Area (Karelia Region). Minerals 9(1), 34. https://doi.org/10.3390/min9010034

Kulizhskiy, S.P., Loiko, S.V., Morgalev, Y.N., Istigechev, G.I., Rodikova, A.V., Maron, T.A., 2017. Investigation of Platinum and Nickel Nanoparticles Migration and Accumulation in Soils within the Southeastern Part of West Siberia. Nano Hybrids and Composites 13, 115-122. https://doi. org/10.4028/www.scientific.net/NHC.13.115

Kulizhsky, S., Loyko, S., Lim, A., 2013. Pedotransfer capacity of nickel and platinum nanoparticles in Albeluvisols Haplic in the south-east of the Western Siberia. Eurasian Journal of Soil Science 2, 90-96.
Kurwadkar, S., Pugh, K., Gupta, A., Ingole, S., 2015. Nanoparticles in the environment: Occurrence, distribution, and risks. Journal of Hazardous, Toxic, and Radioactive Waste 3(04014039). https://doi.org/ 10.1061/(ASCE)HZ.2153-5515.0000258

Laumann, S., Micic, V., Lowry, G.V., Hofmann, T., 2013. Carbonate minerals in porous media decrease mobility of polyacrylic acid modified zero-valent iron nanoparticles used for groundwater remediation. Environmental Pollution 179, 53-60. https://doi.org/10.1016/ j.envpol.2013.04.004

Lecoanet, H.F., Bottero, J.Y., Wiesner, M.R., 2004. Laboratory assessment of the mobility of nanomaterials in porous media. Environmental Science and Technology 38(19), 5164-5169. https://doi.org/10.1021/ es0352303

Lim, A.G., Loiko, S.V., Kuzmina, D.M., Krickov, I.V., Shirokova, L.S., Kulizhsky, S.P., Vorobyev, S.N., Pokrovsky, O.S., 2021. Dispersed ground ice of permafrost peatlands: Potential unaccounted carbon, nutrient and metal sources. Chemosphere 266, 128953. https://doi.org/10.1016/j.ch emosphere.2020.128953

Loiko, S.V., Geras’ko, L.I., Kulizhskii, S.P., Amelin, I.I, Istigechev, G.I., 2015. Soil cover patterns in the northern part of the area of aspen-fir taiga in the southeast of Western Siberia. Eurasian Soil Science 48, 359372. https://doi.org/10.1134/S1064229315040067

Ming, F., Chen, L., Li, D., Wei, X., 2020. Estimation of hydraulic conductivity of saturated frozen soil from the soil freezing characteristic curve. Science of the Total Environment 698, 134132. https://doi.org/10.1016/ j.scitotenv.2019.134132

Montalvo, D., Degryse, F., McLaughlin, M.J., 2015. Natural colloidal P and its contribution to plant P uptake. Environmental Science and Technology 49, 3427-3434. https://doi.org/10.1021/es504643f

Montańo, M.D., Lowry, G.V., Von Der Kammer, F., Blue, J., Ranville, J.F., 2014. Current status and future direction for examining engineered nanoparticles in natural systems. Environmental Chemistry 11(4), 351-366. https://doi.org/10.1071/EN14037

Nowack, B., Bucheli, T.D., 2007. Occurrence, behavior and effects of nanoparticles in the environment. Environmental Pollution 150(1), 5-22. https://doi.org/10.1016/j.envpol.2007.06.006

Perel'man, A.I., 1986. Geochemical barriers: theory and practical applications. Applied Geochemistry 1(6), 669-680. https://doi. org/10.1016/0883-2927(86)90088-0

Philippe, A., Schaumann, G.E., 2014. Interactions of dissolved organic matter with natural and engineered inorganic colloids: a review. Environmental Science and Technology 48, 8946-8962. https://doi. org/10.1021/es502342r

PLAZMA, 2015. MVI 001-XMC-2007, FR.1.31.2007.04107. Metodika vypolneniya izmereniy massovykh doley elementov $\mathrm{v}$ gornykh porodakh metodom mass-spektrometrii s induktivno svyazannoy plazmoy [Technique for measuring mass fractions of elements in rocks by inductively coupled plasma mass spectrometry]. Tomsk: Chimiko-analiticheskiy tsentr "PLAZMA". (in Russian).

Polyakov, V.I., Alekseev, I.I., Orlova, K.S., Abakumov, E.V., Kostecki, J., 2020. Water holding capacity of Russian Arctic soils (Lena river delta and Yamal Peninsula). Soil Science Annual 71 (1), 37-46. https://doi. org/10.37501/soilsa/121490

Qiu, E., Wan, X., Qu, M., Zheng, L., Zhong, C., Gong, F., Liu, L., 2020. Estimating Unfrozen Water Content in Frozen Soils Based on Soil Particle Distribution. Journal of Cold Regions Engineering, 34, article № 04020002. https://doi.org/10.1061/(ASCE)CR.1943-5495.0000208

Rajput, V. D., Minkina, T., Sushkova, S., Tsitsuashvili, V., Mandzhieva, S., Gorovtsov, A., Nevidomskyaya, D., Gromakova, N., 2018. Effect of nanoparticles on crops and soil microbial communities. Journal of Soils and Sediments 18, 2179-2187. https://doi.org/10.1007/s11368017-1793-2

Rajput, V., Minkina, T., Sushkova, S., Behal, A., Maksimov, A., Blicharska, E., Ghazaryan, K., Movsesyan, H., Barsova, N., 2020. ZnO and CuO nanoparticles: a threat to soil organisms, plants, and human health. 
Environmental Geochemistry and Health 42, 147-158. https://doi. org/10.1007/s10653-019-00317-3

Rajput, V.D., Minkina, T.M., Behal, A., Sushkova, S.N., Mandzhieva, S., Singh, R., Gorovtsov, A., Tsitsuashvili, V.S., Purvis, W.O., Ghazaryan, K.A., Movsesyan, H.S., 2018a. Effects of zinc-oxide nanoparticles on soil, plants, animals and soil organisms: A review. Environmental Nanotechnology, Monitoring \& Management 9, 76-84. https://doi. org/10.1016/j.enmm.2017.12.006

Reith, F., Cornelis, G., 2017. Effect of soil properties on gold- and platinum nanoparticle mobility. Chemical Geology 466, 446-453. https://doi. org/10.1016/j.chemgeo.2017.06.033

Reith, F., Fairbrother, L., Nolze, G., Wilhelmi, O., Clode, P.L., Gregg, A., Parsons, J.E., Wakelin, S.A., Pring, A., Hough, R., Southam, G., Brugger, J., 2010. Nanoparticle factories: biofilms hold the key to gold dispersion and nugget formation. Geology 38, 843-846. https://doi.org/10.1130/ G31052.1

Rodrigues, S.M., Trindade, T., Duarte, A.C., Pereira, E., Koopmans, G.F., Römkens, P.F.A.M, 2016. A framework to measure the availability of engineered nanoparticles in soils: Trends in soil tests and analytical tools. TrAC Trends in Analytical Chemistry 75, 129-140. https://doi. org/10.1016/j.trac.2015.07.003

Rudnick, R.L., Gao, S., 2003. 3.01 - Composition of the Continental Crust. [In:] Holland, H.D., Turekian, K.K. (Eds.), Treatise on Geochemistry, Elsevier Science, 2003. https://doi.org/10.1016/B0-08-043751-6/03016-4

Shevchenko, V.P., Vorobyev, S.N., Krickov, I.V., Boev, A.G., Lim, A.G., Novigatsky, A.N., Starodymova, D.P., Pokrovsky, O.S., 2020. Insoluble par- ticles in the snowpack of the Ob river basin (western Siberia) a 2800 $\mathrm{km}$ submeridional profile. Atmosphere 11(11), 1184. https://doi. org/10.3390/atmos11111184

Shrivastava, M., Srivastav, A., Gandhi, S., Rao, S., Roychoudhury, A., Kumar, A., Singhal, R.K., Jha, S.K., Singh, S.D., 2019. Monitoring of engineered nanoparticles in soil-plant system: A review. Environmental Nanotechnology, Monitoring and Management 11, 100218. https://doi. org/10.1016/j.enmm.2019.100218

Soil Survey Staff, 2014. Soil survey field and laboratory methods manual. Soil Survey Investigations Report No. 51, Version 2.0. R. Burt and Soil Survey Staff (Eds.). U. S. Department of Agriculture, Natural Resources Conservation Service, Washington.

Southam, G., Lengke, M.F., Fairbrother, L., Reith, F., 2009. The biogeochemistry of gold. Elements 5, 303-307. https://doi.org/10.2113/gselements.5.5.303

Theng, B.K., Yuan, G., 2008. Nanoparticles in the soil environment. Elements 4(6), 395-399. https://doi.org/10.2113/gselements.4.6.395

Vadyunina, A.F., Korchagin, Z.A., 1986. Methods of study of the physical properties of soils. Agropromizdat, Moscow.

Vance, M.E., Kuiken, T., Vejerano, E.P., McGinnis, S.P., Hochella, M.F., Jr., Rejeski, D., Matthew, S.H., 2015. Nanotechnology in the real world: Redeveloping the nanomaterial consumer products inventory. Beilstein Journal of Nanotechnology 6, 1769-1780. https://doi.org/10.3762/ bjnano.6.181

Vorobyova, L. A., 2006. Theory and practice of chemical analysis of soils. GEOS, Moscow. 


\section{Appendix A}

\section{Table A1}

PtNPs concentrations in studied soil columns

\begin{tabular}{|c|c|c|c|c|c|c|}
\hline \multirow[t]{2}{*}{ Site } & \multirow[t]{2}{*}{ Soil name according to WRB 2015} & \multirow[t]{2}{*}{ Column } & \multirow[t]{2}{*}{ Horizon } & \multicolumn{2}{|c|}{ Pt, mg kg-1 } & \multirow[t]{2}{*}{ KPtNPs } \\
\hline & & & & Bottom & Top & \\
\hline \multirow[t]{6}{*}{ L1 } & Luvic Greyzemic Phaeozems (Episiltic, Endoloamic) & $6-1$ & $\mathrm{Bc}$ & 2.01 & 0.01 & 0.5 \\
\hline & & $6-2$ & $\mathrm{Bc}$ & 1.79 & 0.03 & 1.7 \\
\hline & & $6-3$ & $\mathrm{Bc}$ & 0.82 & 0.08 & 9.8 \\
\hline & & $7-1$ & Cca & 0.23 & $<0.01$ & 2.2 \\
\hline & & $7-2$ & Cca & 0.42 & $<0.01$ & 1.2 \\
\hline & & $7-3$ & Cca & 0.41 & 0.03 & 7.3 \\
\hline \multirow[t]{3}{*}{ L2 } & Endoluvic Greyzemic Phaeozems (Episiltic, Endoloamic) & $10-1$ & A & 2.48 & 0.05 & 2.0 \\
\hline & & $10-2$ & A & 6.99 & 0.05 & 0.7 \\
\hline & & $10-3$ & A & 6.44 & 0.07 & 1.1 \\
\hline \multirow[t]{3}{*}{ Bg1 } & Amphiluvic Phaeozems (Epialbic, Episiltic, Endoloamic) & $1-1$ & $\mathrm{Bt}$ & 0.23 & 0.06 & 26.1 \\
\hline & & $1-2$ & $\mathrm{Bt}$ & 0.07 & 0.04 & 57.1 \\
\hline & & $1-3$ & $\mathrm{Bt}$ & 0.08 & 0.08 & 100.0 \\
\hline \multirow[t]{6}{*}{ Bg2 } & Albic Luvisols (Episiltic, Endoloamic) & $4-1$ & $\mathrm{E}$ & 1.74 & 0.06 & 3.4 \\
\hline & & $4-2$ & $\mathrm{E}$ & 0.83 & 0.04 & 4.8 \\
\hline & & $4-3$ & $\mathrm{E}$ & 1.31 & 0.05 & 3.8 \\
\hline & & $5-1$ & $\mathrm{Bt}$ & 0.23 & 0.02 & 8.7 \\
\hline & & $5-2$ & Bt & 0.13 & 0.01 & 3.8 \\
\hline & & $5-3$ & $\mathrm{Bt}$ & 0.50 & 0.02 & 4.0 \\
\hline \multirow[t]{6}{*}{ Bs1 } & Albic Luvisol (Episiltic, Endoclayic, Endocutanic) & $8-1$ & A & 1.95 & 1.29 & 66.2 \\
\hline & & $8-2$ & A & 3.19 & 0.03 & 0.9 \\
\hline & & $8-3$ & A & 3.18 & 0.02 & 0.6 \\
\hline & & $9-1$ & E & 1.81 & 0.04 & 2.2 \\
\hline & & $9-2$ & E & 1.31 & 0.06 & 4.6 \\
\hline & & $9-3$ & $\mathrm{E}$ & 2.13 & 0.03 & 1.4 \\
\hline \multirow[t]{6}{*}{ Bs2 } & Katoluvic Greyzemic Katostagnic Phaeozem (Epiloamic, & $2-1$ & A & 0.15 & $<0.01$ & 3.3 \\
\hline & Endoclayic) & $2-2$ & A & 0.14 & 0.03 & 21.4 \\
\hline & & $2-3$ & A & 0.11 & 0.03 & 27.3 \\
\hline & & $3-1$ & A & 0.11 & $<0.01$ & 4.5 \\
\hline & & $3-2$ & A & 0.08 & $<0.01$ & 6.3 \\
\hline & & $3-3$ & A & 0.03 & $<0.01$ & 16.7 \\
\hline
\end{tabular}

